\title{
Conversion after laparoscopic cholecystectomy in England
}

\author{
Abdulzahra Hussain • Yazan Masannat • \\ Hussein Almusawy $\cdot$ Prakash Sinha
}

Published online: 10 July 2010

(C) Springer Science+Business Media, LLC 2010

We read with great interest the article Conversion After Laparoscopic Cholecystectomy in England published in the Surgical Endoscopy [1]. We appreciate the efforts of the authors to explore the causes for conversion of laparoscopic cholecystectomy (LC) in England. We think the following points are complementary to the educational value of the study:

1. The two parameters for assessing difficult LC are conversion and the iatrogenic injuries. The article assessed some of the factors associated with conversion but did not indicate what types of injuries were encountered in the study group. We are very interested in knowing how many bile duct injuries and other visceral injuries were reported in this national study. In the United States, about 600,000 cases of LC are managed every year as well as approximately 1,800 to 3,600 bile duct injuries per year (incidence, $0.3-0.6 \%$ ) $[2,3]$.

2. The article confirmed several predictive factors for conversion. However, other important factors were not mentioned including upper abdominal adhesions, obesity, liver cirrhosis, cholecysto-enteric fistula, large liver and gallbladder, abnormal anatomy due to
Mirizzi syndrome, choledochal cyst, and cholangiocarcinoma. The significance of these parameters was confirmed in the literature [4]. Awareness of these by the surgical community that performs LC is therefore crucial to the reduction of the conversion rate to a minimum.

We appreciate a kind response from the authors.

Disclosures A. Hussain, Y. Masannat, H. Almusawy, and P. Sinha have no conflicts of interest or financial ties to disclose.

\section{References}

1. Ballal M, David G, Willmott S, Corless DJ, Deakin M, Slavin JP (2009) Conversion after laparoscopic cholecystectomy in England. Surg Endosc 23:2338-2344

2. Ahrendt SA, Pitt HA (2001) Surgical therapy of iatrogenic lesions of biliary tract. World J Surg 25:1360-1365

3. MacFadyen BV, Vecchio R, Ricardo AE, Mathis CR (1998) Bile duct injury after laparoscopic cholecystectomy: the United States experience. Surg Endosc 12:315-321

4. Tang B, Cuschieri A (2006) Conversions during laparoscopic cholecystectomy: risk factors and effects on patient outcome. J Gastrointest Surg 10:1081-1091 